\title{
PERFORMANCE OF COMPUTED TOMOGRAPHIC COLONOGRAPHY FOR THE SCREENING OF COLORECTAL POLYP IN ACROMEGALIC PATIENTS: a prospective study
}

\author{
Odery RAMOS Jr. ${ }^{1}$, César Luiz BOGUSZEWSKI ${ }^{2}$, Sandra TEIXEIRA ${ }^{3}$, Ricardo De BEM ${ }^{4}$, \\ Benito PAROLIM ${ }^{5}$ and João Carlos PROLLA ${ }^{6}$
}

\begin{abstract}
Context - Acromegalic patients have better chances to develop colorectal polyps and cancer and, considered a high-risk group, need to undergo frequent screening examinations. Moreover, in acromegalia, the increased bowel length and the intestinal loop complexity can lead to higher levels of technical difficulties and increase the risks of complications at conventional colonoscopy. Computed tomographic colonography, also known as virtual colonoscopy, is an innovative and secure technology which is revolutionizing the diagnosis of colon and rectum neoplasias. Objective - To analyze computed tomographic colonography performance for the screening of colorectal polyps in acromegalic patients. Methods - A prospective study of 21 asymptomatic acromegalic patients, 12 male and 9 female, average age 49, who underwent computed tomographic colonography and conventional colonoscopy. Computed tomographic colonography was performed with a GE Helical Multislice Computed Tomography Apparatus. Conventional colonoscopy was performed in the same day, without previous knowledge of the computed tomographic colonography diagnostics. The study evaluated the capacity of computed tomographic colonography to detect patients with colorectal polyps and identify each colorectal lesion described by the colonoscopy. Results - In two patients (2/21), conventional colonoscopy was incomplete. However, in all patients computed tomographic colonography was complete. In Phase I ("per patient"), computed tomographic colonography diagnosed eight of the nine patients with colorectal polyps and showed $88 \%$ sensitivity, $75 \%$ specificity and $81 \%$ accuracy. In Phase II ("per polyp"), out of the 21 acromegalic patients included in this study, 12 presented normal findings at conventional colonoscopy. A total of 19 polyps were identified in 9 patients. Ten of the 19 polyps were smaller than $10 \mathrm{~mm}$, and 9 were equal to or larger than $10 \mathrm{~mm}$. Computed tomographic colonography identified 7 of the 9 polyps $\geq 10 \mathrm{~mm}$ described by conventional colonoscopy and only 6 of the 10 small polyps identified at conventional colonoscopy were detected by computed tomographic colonography. The histological analysis of resected lesions revealed 12 tubular adenomas, 6 hyperplastic polyps and 1 colonic tubulo-villous adenoma with an adenocarcinoma focus. Conclusion - The authors present the first reports of computed tomographic colonography in the screening of colorectal polyps in acromegalic patients. In this study, computed tomographic colonography was performed without complications and a complete and safe colorectal evaluation was possible in all acromegalic patients. Moreover, computed tomographic colonography presented good sensitivity, specificity and accuracy for the identification of acromegalic patients with polyps of any size and better results in the diagnosis of large polyps, when they were compared to small polypoid lesions.
\end{abstract}

HEADINGS - Colonography, computed tomographic. Colonoscopy. Acromegaly. Colonic polyps. Rectal neoplasms. Colonic neoplasms.

\section{INTRODUCTION}

Acromegaly is a chronic disease with insidious evolution which equally affects men and women of all ages, with an estimate of incidence and prevalence of 3-4 new cases/ million and 40-70 cases/million, respectively ${ }^{(5)}$.

It is generally accepted that patients with acromegaly are at a moderately increased risk of developing colorectal cancer ${ }^{(16)}$ and, for this reason, many centers all over the world recommend at least one screening colonoscopy to such patients ${ }^{(23)}$. Studies of acromegalic patients show that conventional colonoscopy (CC) is technically difficult to be performed due to the increased bowel length and the loop complexity. These factors increase the risks of complications during colonoscopy in acromegalic patients ${ }^{(6)}$.

\footnotetext{
Study developed at the "Hospital de Clínicas of the Universidade Federal do Paraná" and "Centro de Tomografia Computadorizada de Curitiba, PR, Brazil" under the Coordination of the Post-Graduate Program in Gastroenterology of the "Universidade Federal do Rio Grande do Sul", in Porto Alegre, RS, Brazil.

${ }^{1}$ Department of Gastroenterology, "Faculdade de Medicina, Universidade Federal do Paraná" FM-UFPR; ${ }^{2}$ Department Endocrinology, FM-UFPR: ${ }^{3}$ Endoscopy Service, "Hospital de Clínicas" HC-UFPR; ${ }^{4}$ Gastroenterology Service, HC-UFPR; ${ }^{5}$ Center of Computed Tomography of Curitiba, PR; ${ }^{6}$ Post-Graduate Studies in Gastroenterology, Universidade Federal do Rio Grande do Sul, Porto Alegre, RS, Brazil.

Correspondence: Dr. Odery Ramos Junior - Rua Saldanha Marinho, 1422 -80430-160 - Curitiba, PR, Brazil. E-mail: oderyramos@gmail.com
} 
The most feared complication related to colonoscopy is perforation $^{(3)}$ and $50 \%$ of these patients require surgery, with a concomitant increase in morbidity ${ }^{(28)}$. Perforation, on its turn, depends on whether polypectomy and/or biopsy is performed, the endoscopist's experience, and in theory, the length of the large intestine, technical difficulties, and the time used for the colonoscopic procedure ${ }^{(28)}$.

Decisions related to colonoscopy policies should also consider potential risks and benefits. The risk of death related to colonoscopy for the general population is 1 in every 10,000 exams $^{(15)}$. In acromegalic patients the estimate death rate associated with the colonoscopic procedure can be as high as 1 in 2,898 procedures. Considering risk and benefit, the cost/benefit rate is high, meaning that in every five deaths prevented by means of a colonoscopic screening in acromegalic patients, there is a theoretical risk of one death due to screening procedures ${ }^{(15)}$. These observations must be considered when we propose developing a screening strategy for colorectal neoplasia in acromegalic patients.

Computed tomographic colonography (CTC), also named virtual colonoscopy, is an innovative technology which is revolutionizing the diagnosis of colon and rectum cancers. Described by VINING et al. ${ }^{(26)}$ in 1994 , this technique has been researched widely in the last years. CTC has presented promising initial results for the detection of colorectal polyps and cancers, offering safety and possibility to evaluate the whole colon structure without sedation or anesthesia. However, this procedure is exclusively a diagnostic one, so therapeutic CC is necessary when positive results are obtained.

The acknowledgment of adenoma and colorectal cancer risks in acromegaly, associated with the technical difficulties and potential complications at $\mathrm{CC}$ in these patients and the recent advances in virtual imaging technologies have led the authors to study the CTC contribution for colorectal evaluation in acromegalic patients and analyze its performance to diagnose acromegalic patients who developed colorectal neoplasia, as well as its capacity to identify each colorectal lesion detected by CC.

\section{METHODS}

\section{Subjects}

From August 2005 to April 2007, 21 acromegalic patients, assisted at the Neuroendocrinology and Metabolism Service of the Clinic Hospital, "Universidade Federal do Paraná" (HCUFPR), Curitiba, PR, Brazil, underwent both CTC and CC, on the same day, to screen for polyps and colorectal cancer. Twelve of the 21 acromegalic patients were male and 9 female, average age 49 . The youngest was 35 and the oldest 65 . CTC was performed at CETAC - Center of Computed Tomography of Curitiba - by a radiologist, graduated from the Brazilian College of Radiology, and with a learning curve for CTC performed in 60 non-acromegalic patients recommended to undergo CC. $\mathrm{CC}$ was performed at the Digestive Endoscopy Unit of the HCUFPR, by an endoscopist graduated from SOBED - Brazilian Society of Digestive Endoscopy. All patients were informed about the purpose of the study, and only the ones who signed the consent form were selected. The project was approved by the Committee of Ethics and Research on Human Beings of HC-UFPR, protocol CEP/HC 941.171/2004-10.

\section{Methods}

Intestinal preparation for CTC and $\mathrm{CC}$ was the same. A liquid diet without residues, prescribed for a period of 48 hours, included the oral intake of 1 liter of $20 \%$ mannitol solution and one additional liter of water administered at least 12 hours before the examination. After intestinal cleaning, the colon distension was performed by means of insufflation of approximately 1.2 to 1.8 liters of atmospheric air trying to avoid any patient discomfort. The patient was laid in a dorsal decubitus position. An image was obtained to verify whether distension was appropriate, and additional air was insufflated, if necessary. Further, computed tomography of the whole abdomen and pelvis was performed during a breath pause. The same procedure was performed with the patient in ventral decubitus position.

CTC was performed with a GE Helical Multislice Computed Tomography Apparatus. CC was performed with an Olympus Apparatus, Model V 160, coupled to a video system which generated images by means of a charge coupled device (CCD), placed at the distal extremity and the images obtained were further digitalized and reproduced on a TV screen, without being magnified or stained.

The findings described at $\mathrm{CC}$ as well as at CTC were evaluated according to the characteristics of each colorectal lesion, number, location and diameter. At CTC, each polyp diameter was measured in $3 \mathrm{D}$ with an electronic ruler and at CC, the length of an open biopsy tweezers, estimated at $5 \mathrm{~mm}$, was used as a measurement reference. To determine the location of each lesion, colorectal evaluation was divided into six segments: rectum, sigmoid, descendent, transverse, ascendant e cecum.

$\mathrm{CC}$ was considered incomplete when, for any reason, the equipment was not able to reach the cecum. CTC, on the other hand, was considered incomplete when at least one colon segment could not be studied appropriately.

CTC techniques and reviews were determined according to conventional protocols ${ }^{(21)}$. Helical multislice computed tomography images were taken from the abdomen and the pelvic region. Images were obtained by means of $5 \mathrm{~mm}$ collimation, at $2.5 \mathrm{~mm}$ increments, at $110 \mathrm{~mA}$ and $110 \mathrm{kV}$. Further colonic reconstructions were performed at a GE AW 4.005 workstation, with the GE TEKTRONIK software, version AW 4.0-05.2.5 S017 navigator 3225012684 . The colon segments were analyzed individually, and correlated simultaneously with the axial slices, the multiplanar and tri-dimensional reconstructions, considering the insufflation, topography, caliber, surface and loop walls of these colon segments.

Data were transferred to a workstation, where the images were analyzed by a radiologist. With the help of the software, a fly-through examination in the colon was performed. When the examination was completed and a report issued, the patient underwent $\mathrm{CC}$ to take advantage of the same bowel preparation.

Patients' preference for CTC over CC was evaluated by means of a questionnaire comprised of opinion-based questions about each of the performed examination methods. 


\section{Statistical analysis}

As acromegaly is not very frequent, we have selected all eligible patients from the Neuroendocrinology Service, at the HC-UFPR. The statistical analysis comprised determination of CTC sensitivity, specificity, positive and negative predictive values, and accuracy in relation to the number of acromegalic patients with colorectal polyps.

\section{RESULTS}

In two patients, CC was incomplete. In both cases, CTC was complete for the evaluation of all colon segments and did not detect lesions in the colonic segments not reached by $\mathrm{CC}$. In one case, CTC identified a $10 \mathrm{~mm}$ polyp confirmed by $\mathrm{CC}$ in the descendant colon and did not detect other lesions in the right colon. In the other patient, CTC evaluated all the colonic segments not reached by CC, without detecting any lesion, thus complementing the colon screening which could not be performed at CC.

Phase - I ("per patient") - When CTC capacity to diagnose colorectal polyps of any size in acromegalic patients was considered (Table 1), nine of the acromegalic patients presented polyps, eight of them diagnosed at CTC (Figure 1), with one false negative. Twelve patients did not present polyps: 9 were confirmed at CTC, and 3 patients presented false positive results. Seven of the nine patients with polyps presented polyps equal to or higher than $10 \mathrm{~mm}$; six of them were diagnosed at CTC. Out of the 14 patients who did not present large polyps, CTC

TABLE 1. Sensitivity (SE), specificity (SP), positive predictive value (PPV), negative predictive value (NPV), and accuracy of CTC according to the number of acromegalic patients who present polyps of any size detected by means of both methods

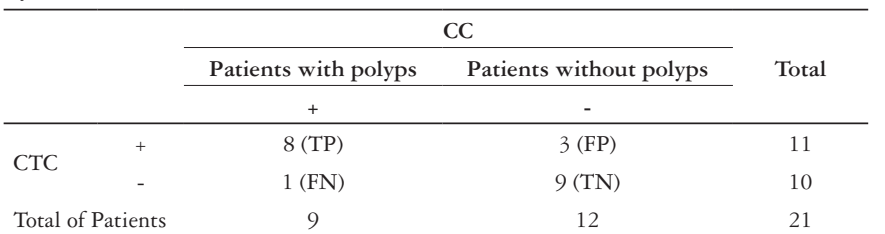

$\mathrm{CC}=$ conventional colonoscopy; $\mathrm{CTC}=$ computed tomographic colonography

$\begin{array}{ll}\text { Sensitivity }=0.88(95 \% \text { IC: } 0.65,0.97) & \text { TP }=\text { true positive } \\ \text { Specificity }=0.75(95 \% \text { IC: } 0.570 .81) & \text { TN = true negative }\end{array}$

$\begin{array}{ll}\text { Specificity }=0.75(95 \% \text { IC: } 0.57,0.81) & \mathrm{TN}=\text { true negative } \\ \text { Positive predictive value }=0.72(95 \% \text { IC: } 0.53,0.80) & \mathrm{FP}=\text { false positive }\end{array}$

Negative predictive value $=0.90$ (95\% IC: $0.68,0.98) \quad \mathrm{FN}=$ false negative

Negative predictive value $=0.90(95 \%)$
Accuracy $=0.81$ ( $95 \%$ IC: $0.60,0.88)$

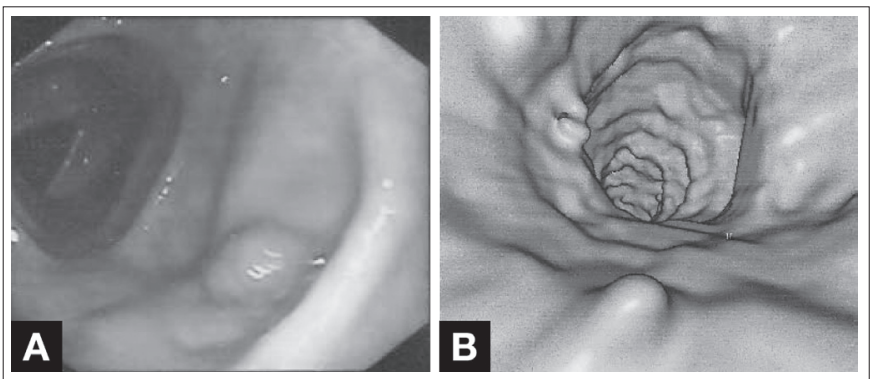

FIGURE 1. Acromegalic patient with polyp in the sigmoid colon, at CC (a) and CTC (b) confirmed 12 of them and revealed 2 false positives. Out of the nine patients who presented polyps, six presented polyps smaller than $10 \mathrm{~mm}$, four of them detected at CTC. The 15 acromegalic patients who did not present polyps of this size, only 1 had the polyp diagnosed at CTC. There was one false positive and two false negative.

Phase - II ("per polyp") - Analysis of CTC was also performed based on the identification of each colorectal polyp, according to its diameter, reported at $\mathrm{CC}$, in the acromegalic patients (Figure 2). Out of the 21 acromegalic patients included in this study, 12 presented normal findings at CC. A total of 19 polyps were identified in 9 patients. Ten of the 19 polyps were smaller than $10 \mathrm{~mm}$, and 9 were equal to or larger than $10 \mathrm{~mm}$ (Figure 3). There were four false negative and one false positive results for $<10 \mathrm{~mm}$ polyps. Only six small polyps identified at $\mathrm{CC}$ were detected by CTC. The false positive result in the re-evaluation of the CTC images was considered a residue and four $<10 \mathrm{~mm}$ polyps were not identified even after a careful CTC re-evaluation examination was performed. When we studied the reasons for the two false negative results for $\geq 10 \mathrm{~mm}$ polyps at CTC, a further analysis of CTC images revealed that one image was interpreted as a thick fold in the sigmoid and the other undetected polyp was interpreted as a residue. The two false positive findings of $\geq 10 \mathrm{~mm}$ polyps at CTC are accounted for as a wrong interpretation of the residues as polyps.

The 19 identified polyps were dissected successfully and examined histologically: 12 were adenomatous and 6
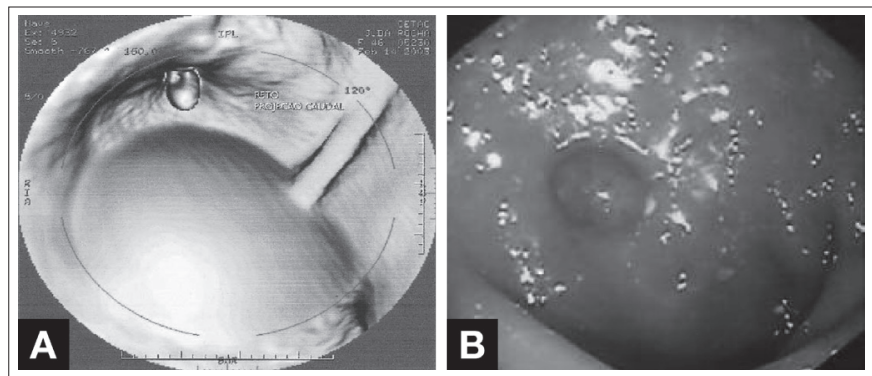

FIGURE 2. Rectal polyp identified at CTC (a) three-dimensional and confirmed at CC (b)

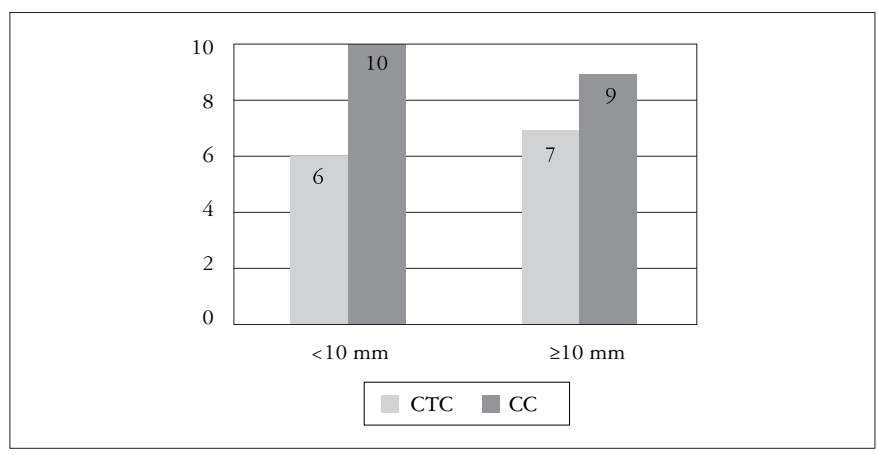

FIGURE 3. Comparison between the total number of polyps $<10 \mathrm{~mm}$ and polyps $\geq 10 \mathrm{~mm}$ detected at CTC and CC in acromegalic patients 
hyperplastic (Table 2). In a 65-year old male patient, with 30 year acromegaly but no symptomatic colorectal disease, CTC detected a $15 \mathrm{~mm}$ polypoid lesion in the transverse colon. This finding was confirmed at CC. The polyp was dissected and the anatomopathologic diagnostic revealed a tubulo-villous colonic adenoma with a multifocal high-degree epithelial dysplasia and a focus of well-differentiated adenocarcinoma.

TABLE 2. Results of histological analysis of polyps removed from acromegalic patients

\begin{tabular}{|c|c|c|c|}
\hline \multicolumn{4}{|c|}{ Histology of colorectal lesions } \\
\hline $\begin{array}{c}\text { Total } \\
\mathrm{n}=19\end{array}$ & $\begin{array}{c}\text { Tubular } \\
\text { adenoma } \\
\mathrm{n}=12\end{array}$ & $\begin{array}{c}\text { Hyperplastic } \\
\text { polyps } \\
\mathrm{n}=6\end{array}$ & $\begin{array}{l}\text { Colorectal cancer } \\
\qquad \mathrm{n}=1\end{array}$ \\
\hline
\end{tabular}

\begin{tabular}{lcccc}
\hline Diameter & & & & \\
$<10 \mathrm{~mm}$ & 10 & 6 & 4 & - \\
Polyps $\geq 10 \mathrm{~mm}$ & 9 & 6 & 2 & $1 *$ \\
\hline
\end{tabular}

*Obs.: Colonic tubulo-villous adenoma with a well differentiated adenocarcinoma focus

(intramucous and with lesion-free pedicle)

\section{DISCUSSION}

CTC or "virtual colonoscopy" has been widely used for large bowel imaging. It can offer more advantages over the conventional colonoscopy for the screening of colorectal cancer due to its less invasive nature and the lack of sedation and recovery time.

Most of the studies conducted on CTC have compared it to colonoscopy for the detection of polyps and colorectal cancer. In a study performed with 1,233 asymptomatic patients, employing fecal tagging and postacquisition digital subtraction of residual stool and fluid from the lumen the sensitivity per polyp obtained for CTC in relation to adenomas of $6 \mathrm{~mm}, 8 \mathrm{~mm}$ and at least $10 \mathrm{~mm}$ in diameter was $85.7 \%, 92.6 \%$, and $92.2 \%$, respectively. All per-patient values were slightly higher than the per-polyp results. CTC specificity was $96 \%$ for adenomas of at least $10 \mathrm{~mm}$ in diameter, $92.2 \%$ for those of at least $8 \mathrm{~mm}$ diameter, and $79.6 \%$ for polyps of at least $6 \mathrm{~mm}$ diameter. The two malignant polyps found were detected by CTC. These findings suggest that computed tomographic colonoscopy can be very sensitive and specific for the detection of adenomas and present a result very similar to colonoscopy when the technique is performed by experts employing fecal tagging, electronic bowel cleansing, and tridimensional image review ${ }^{(14)}$.

Another classic comparative study performed in nine centers in the United States and one in the United Kingdom, involving a cohort of 615 patients, employed standard CTC protocol without fecal tagging. Lesions of at least $10 \mathrm{~mm}$ were detected in 42 of 615 patients, revealing sensitivity of $55 \%$ and the specificity for all the lesions was above $90 \%$. This study has been criticized for including radiologists that were not experienced with the CTC technique. The authors supported this argument and acknowledged that the Center which recruited most participants reported a much higher sensitivity ( $82 \%$ ) than the other centers for the detection of $>10 \mathrm{~mm}^{\text {lesions }}{ }^{(4)}$.

Researchers have been developing new electronic methods for the removal of residual stool and colon cleansing ${ }^{(27,29)}$. The ability to perform CTC with reduced or no purgation, while maintaining acceptable diagnostic accuracy, would make it, from the patients' perspective, a likely technique for bowel screening ${ }^{(13)}$. Moreover, computer-aided detection of polyps can improve the method sensitivity regardless of the reviewer's experience and reduce the reporting time ${ }^{(2,19,20)}$.

When considering how screening with CTC can be implemented, the definition of "significant lesion" must be established. The issue involving polyp size becomes critical if CTC is employed for the screening of colorectal neoplasia. CTC does not routinely reveal small lesions. Nonetheless, if CTC were able to reveal a significant number of small lesions, it would generate many unnecessary colonoscopies, as most of these small lesions would be nonadenomatous, and the method would prove not to be cost effective. For CTC to be adopted as a screening procedure, the small lesions should be ignored or, if detected, investigated at adequate surveillance intervals $(1,10,18,24)$.

In a recent published trial ${ }^{(8)}, \mathrm{CTC}$ screening was performed in 3,120 patients and compared with 3,163 patients who underwent CC. Both groups were at high-risk for colorectal neoplasia. In the $\mathrm{CC}$ cohort, 2,434 polypectomies were performed, that is, all the detected polyps were resected. Seven colonic perforations were reported. In the CTC cohort it was established that only $>6 \mathrm{~mm}$ polyps would be resected and 561 polyps fell into this category. In this group, no complications were reported. The authors concluded that CTC results in the detection of advanced neoplasia are similar when compared to CC. Thus, they suggest that screening should first be performed with CTC followed by therapeutic CC, if necessary.

The European Society of Gastrointestinal Radiology (ESGAR) has recently published hands-on CTC training programs and has claimed that CTC has outperformed barium enema, and has gained wider acceptance among radiologists and gastroenterologists ${ }^{(22)}$.

Hence, CTC has been proposed for colon and rectum diagnostic studies specially for the evaluation of the colon above the obstructed segment ${ }^{(9)}$, colon evaluation after unsuccessful conventional colonoscopy ${ }^{(11)}$, patients with higher risks of colonic perforation, anesthetic complications, and colorectal neoplasia screening in risk-factor populations ${ }^{(7,25)}$.

Endocrinologists have acknowledged, for a long time, that acromegalic patients run an increased risk to develop neoplasia, mainly in the large bowel. The benefits and risks incurred from repeated colonoscopies for colorectal evaluation in acromegalic patients have been investigated due to the peculiarities associated with the bowel dimensions and the frequent formation of complex intestinal loops, conditions which make the procedure a challenging one, with higher levels of technical difficulties and possibilities to develop potential complications ${ }^{(17)}$.

In this study, $\mathrm{CC}$ was performed as control on acromegalic patients, and the endoscopist described that there were some difficulties to pass through the sigmoid colon with the colonoscope. In two cases, due to redundant intestinal loops, despite the several maneuvers tried, colonoscopy could not be completed. The examinations were interrupted to avoid potential risks and complications. CTC in these two patients was complete; however, because of the complexity of the intestinal loops, more time was 
necessary to interpret the data collected. The two patients whose $\mathrm{CC}$ was not complete and whose CTC did not detect any lesions were recommended for a follow-up procedure after 1 year.

In Phase I (per patient), the authors analyzed the diagnostic of acromegalic patients with polyps of any size. The results of the 21 CTC were classified as 8 true positive, 9 true negative, 3 false positive and 1 false negative results. The performance per patient improved as the polyp size increased. With $<10 \mathrm{~mm}$ polyps, sensitivity decreased significantly. We point out that in the per-patient analysis only the lesions which were combined with the polyps at $\mathrm{CC}$ were considered true positive findings. We consider that the results obtained with the per-patient approach are more important since the purpose is to identify only the patients who might need to undergo colonoscopy.

The patient with colonic tubulo-villous adenoma with a well differentiated adenocarcinoma focus, resected by $\mathrm{CC}$, was also diagnosed correctly by CTC. Consequently, the authors acknowledge that CTC was able to detect colorectal cancer in this acromegalic patient.

In this study, around $20 \%$ (4/21) of the acromegalic patients reported that they had not obtained a good response from the preparation used to cleanse the bowel. In these cases, it was necessary to repeat the same mannitol dose determined by the protocol to perform CTC and CC. All colonic segments could be evaluate by CTC and CC appropriately. However, the presence of residues contributed to false positive findings. This situation was also described by RENEHAN et al. ${ }^{(17)}$ who associated this difficulty in cleansing the bowel with a longer colonic transit time in acromegalic patients and suggested, as we have done, that the standard cleansing for colon preparation can be inappropriate for such patients. For this reason, the authors suggest that acromegalic patients should undergo a longer diet without residues and should receive a larger amount of laxative for colon cleansing.

In our study, despite the abdominal discomfort reported by a small number of patients during colon insufflation, the tolerance of CTC, compared to CC, was considered satisfactory, revealing a preference of $67 \%$ among the acromegalic patients. The sedation and the need to accompany the patients to perform the examination were some of the complaints and concerns about CC. Additionally, the results are potentially limited due to subjective and non-validated questionnaires.

When CTC analysis was performed per polyp, the low sensitivity obtained for the small polyps in this study was also shown in non-acromegalic patients ${ }^{(4)}$. It is no surprise to find out that CTC can better detect large polyps - larger than
$10 \mathrm{~mm}$ - than smaller polyps. However, the definition of what constitutes a clinically important polyp in regard to its size and morphology is very important to evaluate CTC accuracy. It is a debatable issue ${ }^{(1)}$.

There are two limitations that need to be acknowledged and addressed regarding the present study. The first one concerns the small cohort of patients in this study due to the low prevalence of acromegaly accounts. However, the authors register the multiprofessional initiative to conduct this study and demonstrate the feasibility of performing CTC to detect colorectal adenoma in acromegalic patients. Another limitation is the radiologist's experience which can be considered limited by a short learning curve due to CTC availability and cost in our region. This fact may have influenced the false positive and negative results. The authors believe that the adoption of CTC as a research method in graduate programs is one of the ways to make the method economically feasible and contribute to improve the learning curve among the gastroenterologists and radiologists.

New advances in CTC, such as the new software V3D Colon System developed by Dr. Pickhardt's team in Madison, Wisconsin, $\mathrm{USA}^{(13)}$, and the automatic computer capture system of polyps can improve the method sensitivity, regardless of the examiner's experience, and reduce the time necessary to interpret the exam ${ }^{(2)}$. It is expected that this new perspectives will bring consensus to the use of CTC in the clinical practice setting ${ }^{(22)}$.

In this study, CTC performed a complete colorectal evaluation, without any complications, in all acromegalic patients. Moreover, it presented good sensitivity, specificity and accuracy for the identification of acromegalic patients with any size polyps and better results in the diagnosis of large polyps, when they were compared to small polypoid lesions.

\section{ACKNOWLEDGEMENTS}

We are grateful to Professor Dr. Júlio Cesar Pisani of the Gastroenterology Service and Dr. Anke Boeving of the Neuroendocrinology Service of the "Hospital de Clínicas", Universidade Federal do Paraná, for their active participation and decisive contribution for the outcome of this study. We also thank Professor Dr. Juarez Gabardo for the statistical analysis of the study and Professor Dr. Guilberto Minguetti, of the Computed Tomographic Center, for his technical support. Our special thanks to the Post-Graduate Program in Gastroenterology of the Universidade Federal do Rio Grande do Sul for the support offered to develop this project. 
Ramos Jr O, Boguszewski CL, Teixeira S, De Bem R, Parolim B, Prolla JC. Desempenho da colonografia tomográfica computadorizada para o rastreamento de pólipo colorretal em pacientes acromegálicos: um estudo prospectivo. Arq Gastroenterol. 2009;46(2):90-6.

RESUMO - Contexto - Pacientes com acromegalia apresentam maiores chances de desenvolver pólipo e câncer colorretal e, sendo considerados integrantes do grupo de risco, necessitam serem submetidos aos exames de rastreamento. Por sua vez, na acromegalia, o maior comprimento do cólon e a formação de alças intestinais complexas podem prever maiores dificuldades técnicas e aumentar o risco em potencial de complicações durante o exame de colonoscopia convencional. A colonografia tomográfica computadorizada, também denominada colonoscopia virtual, é uma tecnologia inovadora e segura, que está revolucionando o diagnóstico das neoplasias do cólon e do reto. Objetivo - Analisar o desempenho da colonografia tomográfica computadorizada no rastreamento de pólipos colorretais em pacientes com acromegalia. Métodos - Estudo prospectivo com 21 pacientes acromegálicos, 12 do sexo masculino e 9 do sexo feminino, idade média de 49 anos, assintomáticos, submetidos a colonografia tomográfica computadorizada e colonoscopia convencional. A colonografia tomográfica computadorizada foi realizada com aparelho de tomografia computadorizada helicoidal multislice da marca GE. A colonoscopia convencional foi realizada, no mesmo dia, sem prévio conhecimento do diagnóstico da colonografia tomográfica computadorizada. O estudo avaliou a capacidade da colonografia tomográfica computadorizada para detectar pacientes acromegálicos com pólipos colorretais e a identificação de cada lesão colorretal descrita pela colonoscopia. Resultados - Em dois pacientes (2/21) a colonoscopia convencional foi incompleta. Entretanto, em todos os pacientes a colonografia tomográfica computadorizada foi completa na avaliação colorretal. Na primeira fase ("por paciente"), a colonografia tomográfica computadorizada diagnosticou oito de nove pacientes com pólipos colorretais e mostrou $88 \%$ de sensibilidade, $75 \%$ de especificidade e $81 \%$ de precisão. Na segunda fase ("por pólipo"), dos 21 pacientes acromegálicos incluídos no estudo, 12 apresentaram colonoscopia convencional normal. Um total de 19 pólipos foram identificados em 9 pacientes. Dez dos 19 pólipos eram menores que $10 \mathrm{~mm}$ e 9 foram iguais ou maiores que $10 \mathrm{~mm}$. A colonografia tomográfica computadorizada identificou 7 dos 9 pólipos $\geq 10 \mathrm{~mm}$ descritos pela colonoscopia convencional e somente 6 dos 10 pólipos pequenos detectados pela colonoscopia convencional. A análise histológica das lesões ressecadas revelaram 12 adenomas tubulares, 6 pólipos hiperplásicos e 1 adenoma túbulo-viloso com um foco de adenocarcinoma. Conclusão - São apresentados os primeiros relatos da realização de colonografia tomográfica computadorizada no rastreamento de pólipos colorretais em doentes com de acromegalia. Neste estudo, a colonografia tomográfica computadorizada realizou avaliação colorretal completa e sem complicações em todos os pacientes acromegálicos. A colonografia tomográfica computadorizada apresentou boa sensibilidade, especificidade e precisão para identificar pacientes acromegálicos com presença de pólipos colorretais de qualquer diâmetro e melhores resultados no diagnóstico de pólipos grandes quando comparados com pequenas lesões polipóides.

DESCRITORES - Colonografia tomográfica computadorizada. Colonoscopia. Acromegalia. Pólipos do colo. Neoplasias retais. Neoplasias do colo.

\section{REFERENCES}

1. Aldridge AJ, Simson JN. Histological assessment of colorectal adenomas by size: are polyps less than $10 \mathrm{~mm}$ in size clinically important? Eur J Surg. 2001;167: 777-81.

2. Baker ME, Bogoni L, Obuchowski NA, Dass C, Kendzierski RM, Remer EM, Einstein DM, Cathier P, Jerebko A, Lakare S, Blum A, Caroline DF, Macari M. Computeraided detection of colorectal polyps: can it improve sensitivity of less-experienced readers? Preliminary findings. Radiology. 2007;245:140-9.

3. Bowles CJ, Leicester R, Romaya C, Swarbrick E, Williams CB, Epstein O. A prospective study of colonoscopy practice in the UK today: are we adequately prepared for national colorectal cancer screening tomorrow? Gut. 2004;53:277-83.

4. Cotton PB, Durkalski VL, Pineau BC, Palesch YY, Mauldin PD, Hoffman B, Vining DJ, Small WC, Affronti J, Rex D, Kopecky KK, Ackerman S, Burdick JS, Brewington C, Turner MA, Zfass A, Wright AR, Iyer RB, Lynch P, Sivak MV, Butler H. Computed tomographic colonography (virtual colonoscopy): a multicenter comparison with standard colonoscopy for detection of colorectal neoplasia. JAMA. 2004;291: 1772-4.

5. Holdaway IM, Rajasoorya C. Epidemiology of acromegaly. Pituitary. 1999;2:29-41.

6. Jenkins PJ, et al. Acromegaly is associated with colonomegaly which correlates with tissue exposure to growth hormone and may be implicated in their increased risk of colorectal neoplasia [abstract]. J Endocrinol. 1997;155(suppl 2).

7. Johnson CD, Harmsen WS, Wilson LA, Maccarty RL, Welch TJ, Ilstrup DM, Ahlquist DA. Prospective blinded evaluation of computed tomographic colonography for screen detection of colorectal polyps. Gastroenterology. 2003;125:311-9.

8. Kim DH, Pickhardt PJ, Taylor AJ, Leung WK, Winter TC, Hinshaw JL, Gopal DV, Reichelderfer M, Hsu RH, Pfau PR. CT colonography versus colonoscopy for the detection of advanced neoplasia. N Engl J Med. 2007;357:1403-12.

9. Morrin MM, Farrell RJ, Raptopoulos V, McGee JB, Bleday R, Kruskal JB. Role of virtual computed tomographic colonography in patients with colorectal cancers and obstructing colorectal lesions. Dis Colon Rectum. 2000;43:303-11.
10. Morrin MM, LaMont JT. Screening virtual colonoscopy — ready for prime time? N Engl J Med. 2003;349:2261-4.

11. Neri E, Giusti P, Battolla L, Vagli P, Boraschi P, Lencioni R, Caramella D, Bartolozzi C. Colorectal cancer: role of CT colonography in preoperative evaluation after incomplete colonoscopy. Radiology. 2002;223:615-9.

12. Pickhardt PJ. Three-dimensional endoluminal CT colonography (virtual colonoscopy): comparison of three commercially available systems. Am J Roentgenol. 2003;181: 1599-606.

13. Pickhardt PJ, Choi JH. Electronic cleansing and stool tagging in CT colonography: advantages and pitfalls with primary three-dimensional evaluation. Am J Roentgenol. 2003;181:799-805

14. Pickhardt PJ, Choi JR, Hwang I, Butler JA, Puckett ML, Hildebrandt HA, Wong RK, Nugent PA, Mysliwiec PA, Schindler WR. Computed tomographic virtual colonoscopy to screen for colorectal neoplasia in asymptomatic adults. N Engl J Med. 2003;349:2191-200.

15. Renehan AG, Odwyer ST, Shalet SM. Screening colonoscopy for acromegaly in perspective. Clin Endocrinol (Oxf). 2001;55:731-3.

16. Renehan AG, O'Connell J, O'Halloran D, Shanahan F, Potten CS, O'Dwyer ST, Shalet SM. Acromegaly and colorectal cancer: a comprehensive review of epidemiology, biological mechanisms, and clinical implications. Horm Metab Res. 2003;35:712-25.

17. Renehan AG, Painter JE, Bell GD, Rowland RS, O'Dwyer ST, Shalet SM. Determination of large length and loop complexity in patients with acromegaly undergoing screening colonoscopy. Clin Endocrinol (Oxf). 2005;62:323-30

18. Rex DK. Virtual colonoscopy: time for some tough questions for radiologists and gastroenterologists [editorial]. Endoscopy. 2000;32:260-3.

19. Rockey DC, Barish M, Brill JV, Cash BD, Fletcher JG, Sharma P, Wani S, Wiersema MJ, Peterson LE, Conte J. Standards for gastroenterologists for performing and interpreting diagnostic computed tomographic colonography. Gastroenterology. 2007; 133:1005-24

20. Summers RM. Challenges for computer-aided diagnosis for CT colonography. Abdom Imaging. 2002;27:268-74. 
21. Taylor SA, Halligan S, Bartram CI. CT colonography: methods, pathology and pitfalls. Clin Radiol. 2003;58:179-90.

22. Taylor SA, Laghi A, Lefere P, Halligan S, Stoker J. European Society of Gastrointestinal and Abdominal Radiology (ESGAR): consensus statement on CT colonography. Eur Radiol. 2007; 17:575-9

23. Terzolo M, Reimondo G, Gasperi M, Cozzi R, Pivonello R, Vitale G, Scillitani A, Attanasio R, Cecconi E, Daffara F, Gaia E, Martino E, Lombardi G, Angeli A, Colao A. Colonoscopic screening and follow-up in patients with acromegaly: a multicenter study in Italy. J Clin Endocrinol Metab. 2005;90:84-90.

24. Van Dam J, Cotton P, Johnson CD, McFarland BG, Pineau BC, Provenzale D, Ransohoff D, Rex D, Rockey D, Wootton FT 3rd, American Gastroenterological Association. AGA future trends report: CT colonography. Gastroenterology. 2004;127:970-84.

25. Van Gelder RE, Nio CY, Florie J, Bartelsman JF, Snel P, De Jager SW, Van Deventer SJ, Laméris JS, Bossuyt PM, Stoker J. Computed tomographic colonography compared with colonoscopy in patients at increased risk for colorectal cancer. Gastroenterology. 2004; $127: 41-8$.
26. Vining DJ, Gelfand DW, Bechtold RE, Scharling ES, Grishaz EK, Shifrin RY. Technical feasibility of colon imaging with helical CT and virtual reality. Am J Roentgenol. 1994;162(suppl):104.

27. Wexner SD, Garbus JE, Singh JJ, SAGES Colonoscopy Study Outcomes Group. A prospective analysis of 13.580 colonoscopies. Reevaluation of credentialing guidelines. Surg Endosc. 2001;15:251-61.

28. Winawer SJ, Fletcher RH, Miller L, Godlee F, Stolar MH, Mulrow CD, Woolf SH, Glick SN, Ganiats TG, Bond JH, Rosen L, Zapka JG, Olsen SJ, Giardiello FM, Sisk JE, Van Antwerp R, Brown-Davis C, Marciniak DA, Mayer RJ. Colorectal cancer screening: clinical guidelines and rationale. Gastroenterology. 1997;112:594-642.

29. Zalis ME, Perumpillichira J, Hahn PF. Digital subtraction bowel cleansing for CT colonography using morphological and linear filtration methods. IEEE Trans Med Imaging. 2004;23:1335-43.

Recebido em 28/11/2008. Aprovado em 19/3/2009. 